\title{
Beef
}

\section{Effects of harvest maturity and/or kernel processing on corn silage processing score and particle size of corn silage}

\author{
Thomas Hamilton, Julie Walker, Warren Rusche, and Zachary Smith
}

\section{Objective}

A single corn hybrid was used to evaluate harvest maturity (Mat) and/or kernel processing (KP) effects on corn silage processing score (CSPS) and particle size (PS).

\section{Study Description}

Treatments were arranged in a $2 \times 2$ factorial of: 1) Mat (early and late) and 2) KP (no or yes). A single corn field was planted on April 27, 2020. There were 12 loads (experimental unit) per simple effect treatment mean. Data were analyzed as a completely randomized design. Early harvest (3/4 milk line) occurred on August 28, 2020 [yield (as is) $=17.40$ tons/acre; $\mathrm{DM}=43.1 \%$; CP, NDF, and starch $=6.5,46.0$, and $32.9 \%$, respectively (DM basis)]. Late harvest (black layer) occurred on September 9, 2020 [yield = 16.83 ton/acre (as is); DM = $49.2 \%$; CP, NDF, and starch $=6.6,49.8$, and $37.5 \%$, respectively (DM basis)]. The same equipment was used for both Mat with KP achieved by narrowing processing rollers. The CSPS was determined as the proportion of starch retained below a 0.19 in sieve. Grain content (DM basis) of the corn silage was calculated from: starch content/0.72. Particle size was assessed using the Penn State Particle Separator. A Mat $\times$ KP interaction $(P=$ $0.05)$ was detected for CSPS. Early/no and late/no had decreased $(P \leq 0.05)$ CSPS compared to early/yes and late/yes had the greatest CSPS $(P \leq 0.05)$ compared to others. Grain content was $13.9 \%$ greater in late compared to early $(P=0.01)$. A Mat $\times \mathrm{KP}$ interaction $(P=0.03)$ was detected for $\mathrm{PS}$. Early/no had the greatest $(P \leq 0.05) \mathrm{PS}$, early/yes and late/no were intermediate, and late/yes had decreased PS compared to others $(P$ $\leq 0.05)$.

\section{Take Home Points}

These data indicate that Mat and KP influence CSPS synergistically. Producers should consider KP when corn silage is harvested at a later maturity to enhance CSPS.

\section{Acknowledgements}

This research was sponsored in part by National Institute of Food and Agriculture and the South Dakota State University Experiment Station (HATCH- SD0OH690-19).

South Dakota State University Beef Day 2021

(c) 2021 South Dakota Board of Regents 